\title{
How aging of the global population is changing oncology
}

\author{
Yan Fei Gư ${ }^{1}$, Frank P Lin ${ }^{2,3}$ and Richard J Epstein ${ }^{1,2,4, a}$ (iD \\ ${ }^{1}$ New Hope Cancer Center, United Family Hospitals, 9 Jiangtai W Rd, Chaoyang, Beijing 100015, China \\ ${ }^{2}$ Garvan Institute of Medical Research, 384 Victoria St, Darlinghurst, Sydney 2010, Australia \\ ${ }^{3}$ NH\&MRC Clinical Trials Centre, 92 Parramatta Rd, Camperdown, Sydney 2050, Australia \\ ${ }^{4}$ UNSW Clinical School, St Vincent's Hospital, 390 Victoria St, Darlinghurst, Sydney 2010, Australia \\ ahttps://orcid.org/0000-0002-4640-0195
}

\begin{abstract}
Population aging is causing a demographic redistribution with implications for the future of healthcare. How will this affect oncology? First, there will be an overall rise in cancer affecting older adults, even though age-specific cancer incidences continue to fall due to better prevention. Second, there will be a wider spectrum of health functionality in this expanding cohort of older adults, with differences between "physiologically older" and "physiologically younger" patients becoming more important for optimal treatment selection. Third, greater teamwork with supportive care, geriatric, mental health and rehabilitation experts will come to enrich oncologic decision-making by making it less formulaic than it is at present. Success in this transition to a more nuanced professional mindset will depend in part on the development of user-friendly computational tools that can integrate a complex mix of quantitative and qualitative inputs from evidence-based medicine, functional and cognitive assessments, and the personal priorities of older adults.
\end{abstract}

Keywords: clinical decision-making, demography, longevity, quality of life, supportive care

Epidemiologic shifts with impacts on health are occurring worldwide [1-3]. Life expectancies in most countries are rising, reflecting improvements in public health [4, 5], while birth rates are declining with urbanization [6-9]. This upending of the population age pyramid is now raising healthcare concerns due to an expected higher burden of agerelated disabilities and diseases $[10,11]$ with consequent reduction in 'health span' [12, 13]. An inconvenient question is thus raised: does this global transition to a super-aging society [14-16] imply a need to change how medicine is practised today $[17,18]$ ?

Cancer care is a timely focus for this debate [19]. Over the next forty years cancer will create the highest productivity burden of all disease groups as quantified by disabilityadjusted life years, and will also overtake ischemic heart disease as the leading cause of death [20-22]. Even as age-standardized cancer mortality is declining due to better prevention, total cancer diagnoses and death rates are continuing to rise, with population aging the single main cause $[23,24]$.

Policies have been created to improve cancer care for older adults [25-27] in response to the realization that standard guidelines cannot define optimal management for all

Correspondence to: Richard J Epstein Email: richard.epstein@ufh.com.cn

ecancer 2021, 15:ed119

https://doi.org/10.3332/ecancer.2021.ed119

Published: $13 / 12 / 2021$

Received: 04/08/2021

Publication costs for this article were supported by ecancer (UK Charity number 1176307).

Copyright: $(\subset$ the authors; licensee ecancermedicalscience. This is an Open Access article distributed under the terms of the Creative Commons Attribution License (http:// creativecommons.org/licenses/by/4.0), which permits unrestricted use, distribution, and reproduction in any medium, provided the original work is properly cited. 
circumstances $[28,29]$. Such guidelines have largely been based on the heuristic of late-phase randomized trial endpoints, especially overall survival [30], but there are weaknesses of this model from the viewpoint of older patients with cancer [31-33]. First, most trials have elected to treat younger and fitter patients with maximally tolerated drug doses, but by doing so have raised doubts whether the reported benefits are applicable to older people [34,35]. Second, although randomized prospective trials are much respected in evidential terms, their credibility has been eroded by human factors. For example, despite the need to frame research questions with equipoise [36], positive results from clinical trials are favored by most involved parties - pharmaceutical companies [37], physicians [38], patients [39] and the press [40] - with only insurers and government agencies querying this tendency [41, 42].

Dominance of clinical research by industry [43] has likewise selected for biases due to non-publication of negative studies [44, 45], and trial designs favoring statistically significant outcomes $[46,47]$ - even though many such outcomes provide little real-world benefit to patients [48], especially if older [49]. This is consistent with the impression that average trial gains have tended to reduce in recent decades [50, 51], in part due to regulatory frameworks that have made therapeutic incrementalism the safest commercial strategy [52]. These caveats serve to remind us that clinical decisions should be made not by evidence alone, but by honest and self-critical discussion between doctors and patients [53], including older adults with cancer [54].

\section{How treatment decisions are becoming less influenced by chronological age}

As the cohort of older adults with cancer enlarges, a widening spectrum of patient fitness versus frailty is to be expected [55], complicating therapeutic decision-making. A controversy often raised in this context is that the costliest phase of care tends to be the last year [56,57], with even older patients often being prescribed anticancer therapy in the last month of life [58-60]. The solution to this would not seem to lie in implementing policies based on age, which is an unreliable predictor of health status [61], but in applying functional measures [62]. These include metrics of pre-morbid fitness - as approximated by estimated remaining life years without cancer [63] - and of daily activities or coping [64], as assessed by tools such as comprehensive geriatric assessment, which includes an evaluation of comorbidities [65-67].

A "physiological age" so derived could be factored into evidence-based cancer and treatment expectations (e.g., estimated remaining life years with cancer, without and with treatment, plus quality of life with or without treatment] to create a decisional process that is not arbitrarily distorted by age $[68,69]$. Assessing older patients with cancer in this function-based way should reduce risks of both over- and undertreatment [70,71]. These risks include those from overreliance on the metric traditionally used by oncologists to assess fitness for drug trials, patient performance status [72]. In relinquishing these imperfect predictors of well-being, however, doctors will need to substitute more informative algorithms or endpoints (Figure 1).

Chronological Model

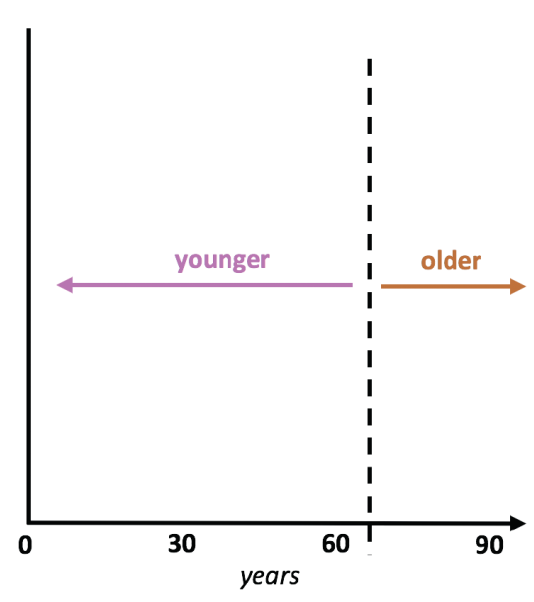

\section{Physiological Model}

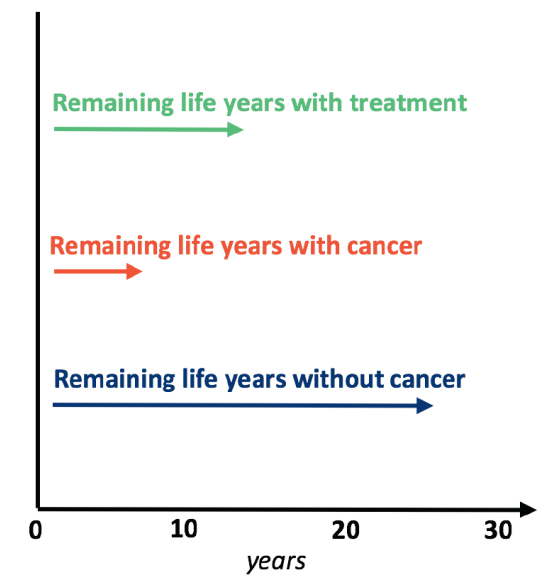

Figure 1. Comparison of the traditional chronological view of aging with a physiological (or "functional", "biological", etc.) viewpoint adapted for patients with a cancer diagnosis. 


\section{How cancer epidemiology is changing as populations are aging}

Mortality from smoking-related malignancies is still rising, but these cancers should decrease as living standards and education improve [73]. In contrast, the epidemic of 'lifestyle cancers' due to overweight and under-exercise shows no hint of abating [74]. As population aging proceeds, lifestyle-related cancers may diverge into two strata: a younger group which more often has cardiovascular disease or diabetes, and an older group whose main risk factor is age alone [75]. The functional extremes, or stereotypes, of older adults with cancer - i.e., physiologically older or physiologically younger - illustrate the breadth of the wellness-illness spectrum in older individuals [76], highlighting the notion of health-related quality of life [77]. Physiologically older patients with cancer are by definition less fit than average for their age, based on non-cancer comorbidity $[78,79]$. An estimate of physiological age is derivable by actuarial calculation of an individual's likely death $x$ years before or after the population's mean life expectancy [80].

Physiologically older vs. younger patients with cancer may also be separated by a wealth-health gradient that steepens with age [81]. The former cohort tends more often to be male, with more comorbidities, fewer financial resources, and more smoking- or inflammation-induced cancers, such as those of the lung, upper esophagus, stomach, bladder or rectum [82]. Physiologically younger patients tend to be more educated or affluent, and more prone to late-onset lifestyle malignancies such as those of the prostate, breast, endometrium, proximal colon, HPV-positive oropharynx, thyroid, or gastro-oesophageal junction; or melanoma, glioma or myeloma [74]. Since the latter patients tend to have fewer competing causes of death [83], they may in future come to comprise the dominant 'older' cohort (Figure 2).

\section{How fewer remaining life years are translating into more patient choices}

Doctors have always modified treatment decisions on a holistic basis - for example, by deciding against morbid surgeries in favor of more conservative even if less curative interventions [84, 85], or by minimizing use of toxic chemotherapies [86]. Such decisions are often justified by patient frailty [31, 87]; however, non-frail older patients may also not receive the most effective therapies due to perceptions that benefits are less worthwhile in individuals with shorter life expectancy [88]. This is analogous to doubts over the use of cancer screening in older adults [89,90], and represents one aspect of a controversy familiar to oncologists - namely, whether doing (or costing) more, in treatment terms, necessarily means doing better [91].

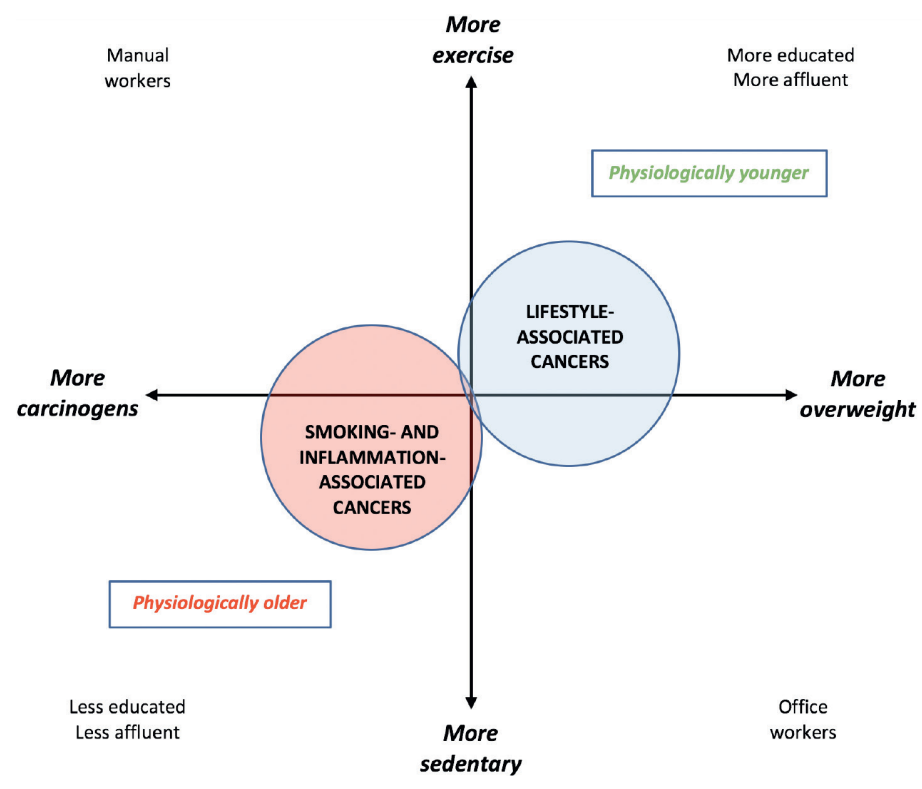

Figure 2. Pathogenetic and socioeconomic interplays relevant to the changing physiological age-specificity of cancer demographics. 


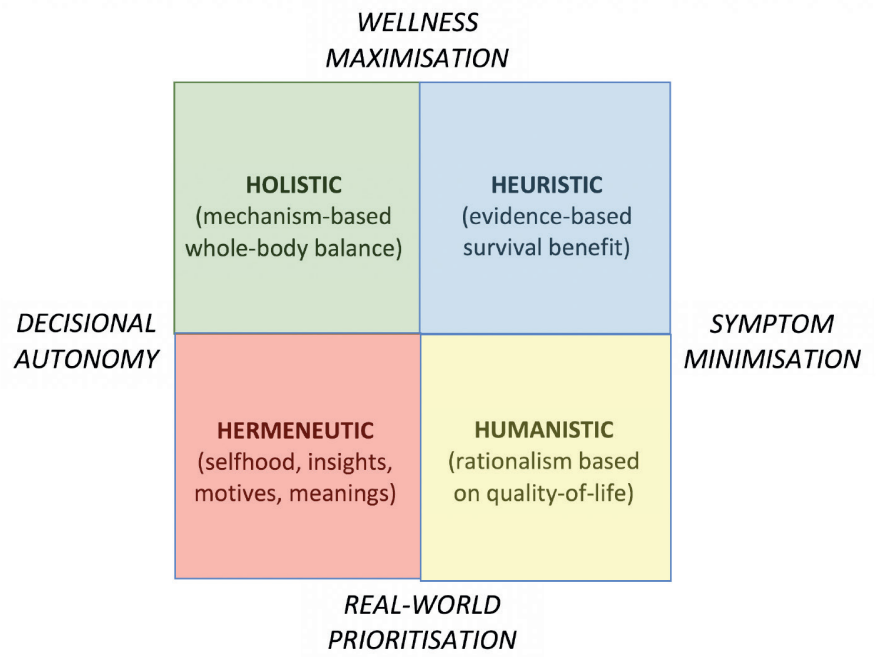

Figure 3. Decision-making schematic showing influence of survival gains balanced with other factors including mechanistic interventions, quality of life strategies, and personal priorities.

Demand will remain strong in all older patient groups for treatment modalities which are perceived, rightly or wrongly, to offer more hope of durable disease control with acceptable toxicity - e.g., molecularly-targeted drugs [92] and immune checkpoint inhibitors [93]. The spectrum of tumors in physiologically older patients tends to be more responsive to immunotherapies [94], even if only in a minority [95], whereas those in the physiologically younger group more often respond to hormonal or targeted drug therapies [96]. The higher educational profile of physiologically younger patients $[97,98]$ will likely favor interest in personalized oncology - i.e., targeted 'smart drugs' which are scientifically plausible [99] but not always empirically testable [100, 101]. So-called theranostic use of ${ }^{177}$ Lu-PSMA-617 radionuclide therapy to treat prostate cancer [102] is one example of a targeted treatment modality that may in future become more widely sought by some older patients - for example, when standard options are exhausted, or are anticipated to be poorly tolerated [103].

This 'healthy aging' cohort also seems likely to embrace mechanism-based non-pharmacologic health initiatives as anticancer interventions [104-106], with these including dietary modification - i.e., caloric restriction [107], fasting or weight loss [108], which inhibit insulin-like growth factor-1/Akt-mediated cancer cell survival [109] - and vigorous daily exercise, which blocks tumors via its effects on AMPK or mTOR signaling [110]. For young and fit patients similar to those recruited for trials, heuristic decision-making based on randomized trials showing survival benefit is appropriate, and for older patients such benefits also remain important [111]. Additional considerations may be prized by older adults, however [112]: these include humanistic prioritization of quality of life [113, 114], holistic balancing of mechanistic interventions with decisional autonomy [115-117], and hermeneutic notions of acceptance and finitude [118, 119] (Figure 3). Hence, one challenge is how to encourage older patients to include these value-adding endpoints in their decision-making without feeling that they are neglecting life-threatening survival priorities.

\section{How the needs of older patients with cancer are driving greater medical teamwork}

The decision-making style of each older cancer patient will vary, ranging from independent to passive [120], but emotion remains a significant factor [121] with reassurance a frequent need [122]. This hints at the influence of incrementalist thinking among patients with cancer, such that even a one-month survival gain persuades many to request more toxic treatments [123], presumably due to fear [124]. Most patients worry about disease recurrence, and look to their oncologist as the ultimate defender against such contingencies [125, 126]; the mantra of whatever can be done will be done, and only the best is good enough, thus becomes a path of least resistance for physicians, and is further reinforced by litigation concerns. Such positivity appears to improve mood and quality of life for newly diagnosed patients with cancer by reducing prognostic awareness [127]. In the longer term, however, decision-making based on risk aversion and anticipated regret 
[128-130] - a response to threatened losses, as used by auctioneers to drive up offers from competing bidders [131, 132] - appears to undermine patient returns [133, 134].

This maladaptive positive feedback loop can be prevented by a team approach incorporating an initial discussion of goals [135]. By admitting fear factors and frequent sources of decision regret [136], older adults may become more able to consider a full range of coping options [137]. Early involvement of supportive, geriatric and/or mental health experts has thus become a standard of care [138-142] which is appreciated by older patients with cancer who value autonomy and dignity [143,144]. For selected patients, religious professionals can also contribute to this team effort [145] - in part, perhaps, because religious people may accept better than doctors that death is a normal part of life, as distinct from its usual secular interpretation as a loss of life or an end to life [146]. Hence, as the age of cancer diagnosis rises, demand for professionals to work together is also likely to rise [147, 148], leading to more cross-disciplinary teamworking and better patient care.

To achieve this vision of a 'geriatric tumor board' [149], it will be ideal to develop computational algorithms able to integrate subspecialty metrics with individualised patient priorities as in Figure 3 [150]. By bridging these qualitative and quantitative dimensions, a validated algorithm could help to give older patients with cancer - plus their carers and doctors - confidence to move away from a cure-seeking to a more cost-effective cure-and-support-seeking culture [151]. As such, this could be a step away from the paradox that cancer costs rise further as knowledge grows, which trend is the opposite of that seen in technological progress as per Moore's Law [152]. However, artificial intelligence approaches to even simple oncological decisions have still to mature [153], suggesting that a quantum leap in digital technologies will be needed to quantify subjective inputs [154]. Device-reported data [155, 156] for monitoring health outcomes in real time [157, 158] provide a fresh dimension of functional analysis for older adults with cancer, but this goal is still far from realization [159]. If and when innovative software eventually yields a systems medicine approach to shared decision-making [160, 161], utilization by third-party payers could create a virtuous pathway to better synergistic team care of older patients [162-165].

\section{Conclusions}

The problems of the modern era have taught the importance of contingency planning. Population aging is a serious and imminent challenge for global healthcare cultures; treating an expanding group of older patients with widely varying fitness levels will demand deep changes to contemporary practices. Steps to ease this transition include the adoption of more informative patient metrics, greater use of function-based assessments, valuing and embracing the personal and spiritual priorities of older patients, and development of informatic infrastructures that can smoothly blend a mix of specialist assessments and patient preferences into 21st-century multidisciplinary cancer care.

\section{Conflicts of interest and funding}

All authors declare no support from any organisation for the submitted work, no financial relationships with any organisations that might have an interest in the submitted work, and no other relationships or activities that could appear to have influenced the submitted work.

\section{Authors' contributions}

The manuscript was conceived and drafted by RJE, was read, criticised and revised through multiple drafts by YFG and FPL, and finally rewritten and approved by all authors. All authors are medical oncologists and PhDs, with FPL having additional expertise in medical informatics, and RJE in drug targeting and clinical trials. The clinical experience of the authors has taken place in Australia, China, Hong Kong, the UK, the USA and Singapore.

\section{Acknowledgments}

Kind support from the family of the late Mr Frank Wolf, and from The St Vincent's Hospital Curran Foundation, is gratefully acknowledged. 


\section{References}

1. Khan HTA (2019) Population ageing in a globalized world: risks and dilemmas? J Eval Clin Pract 25(5) 754-760

2. Song $Z$ and Ferris TG (2018) Baby boomers and beds: a demographic challenge for the ages J Gen Intern Med 33(3) 367-369

3. England K and Azzopardi-Muscat N (2017) Demographic trends and public health in Europe Eur J Public Health 27(suppl_4) 9-13

4. Foreman $\mathrm{KJ}$, Marquez $\mathrm{N}$, and Dolgert A, et al (2018) Forecasting life expectancy, years of life lost, and all-cause and cause-specific mortality for 250 causes of death: reference and alternative scenarios for 2016-40 for 195 countries and territories Lancet 392(10159) 2052-2090

5. Seals DR, Justice JN, and LaRocca TJ (2016) Physiological geroscience: targeting function to increase healthspan and achieve optimal longevity J Physiol 594(8) 2001-2024

6. Mitteldorf JJ and Goodnight C (2013) Post-reproductive life span and demographic stability Biochemistry [Mosc] 78(9) 1013-1022

7. Bhasin S, Kerr C, and Oktay K, et al (2019) The implications of reproductive aging for the health, vitality and economic welfare of human societies J Clin Endocrinol Metab 104(9) 3821-3825

8. Seltzer N (2019) Beyond the great recession: labor market polarization and ongoing fertility decline in the United States Demography 56(4) 1463-1493

9. Vollset SE, Goren E, and Yuan CW, et al (2020) Fertility, mortality, migration, and population scenarios for 195 countries and territories from 2017 to 2100: a forecasting analysis for the Global Burden of Disease Study Lancet 396(10258) 1285-1306

10. Harper S (2014) Economic and social implications of aging societies Science 346(6209) 587-591

11. Prince MJ, Wu F, and Guo Y, et al (2015) The burden of disease in older people and implications for health policy and practice Lancet 385(9967) 549-562

12. Selman C and Swindell WR (2018) Putting a strain on diversity EMBO J 37(22) e100862

13. Fulop T, Larbi A, and Khalil A, et al (2019) Are we ill because we age? Front Physiol 101508

14. Nomura K, Karita K, and Araki A, et al (2019) For making a declaration of countermeasures against the falling birth rate from the Japanese Society for Hygiene: summary of discussion in the working group on academic research strategy against an aging society with low birth rate Environ Health Prev Med 24(1) 14

15. Kim KW and Kim OS (2020) Super aging in South Korea unstoppable but mitigatable: a sub-national scale population projection for best policy planning Spat Demogr 8(2) 155-173

16. Suzuki T (2018) Health status of older adults living in the community in Japan: recent changes and significance in the super-aged society Geriatr Gerontol Int 18(5) 667-677

17. Akashi H, Ishizuka A, and Lee S, et al (2019) The role of the G20 economies in global health Glob Health Med 1(1) 11-15

18. Nakatani H (2019) Population aging in Japan: policy transformation, sustainable development goals, universal health coverage, and social determinates of health Glob Health Med 1(1) 3-10

19. Winckworth-Prejsnar K, McCanney J, and Schatz AA, et al (2019) Policy challenges and opportunities to address changing paradigms in cancer care delivery J Natl Compr Canc Netw 17(5) 424-431

20. Mattiuzzi C and Lippi G (2019) Current cancer epidemiology J Epidemiol Glob Health 9(4) 217-222

21. Global Burden of Disease Cancer C, Fitzmaurice C, and Akinyemiju TF, et al (2018) Global, regional, and national cancer incidence, mortality, years of life lost, years lived with disability, and disability-adjusted life-years for 29 cancer groups, 1990 to 2016: a systematic analysis for the global burden of disease study JAMA Oncol 4(11) 1553-1568 
22. Wu TY, Chung CH, and Lin CN, et al (2018) Lifetime risks, loss of life expectancy, and health care expenditures for 19 types of cancer in Taiwan Clin Epidemiol 10 581-591

23. Aunan JR, Cho WC, and Soreide K (2017) The biology of aging and cancer: a brief overview of shared and divergent molecular hallmarks Aging Dis 8(5) 628-642

24. Nolen SC, Evans MA, and Fischer A, et al (2017) Cancer-incidence, prevalence and mortality in the oldest-old A comprehensive review Mech Ageing Dev 164 113-126

25. Kadambi S, Loh KP, and Dunne R, et al (2020) Older adults with cancer and their caregivers - current landscape and future directions for clinical care Nat Rev Clin Oncol 17(12) 742-755

26. Extermann M, Brain E, and Canin B, et al (2021) Priorities for the global advancement of care for older adults with cancer: an update of the International Society of Geriatric Oncology Priorities Initiative Lancet Oncol 22(1) e29-e36

27. Biganzoli L, Battisti NML, and Wildiers $\mathrm{H}$, et al (2021) Updated recommendations regarding the management of older patients with breast cancer: a joint paper from the European Society of Breast Cancer Specialists [EUSOMA] and the International Society of Geriatric Oncology [SIOG] Lancet Oncol 22(7) e327-e340

28. Woolf SH, Grol R, and Hutchinson A, et al (1999) Clinical guidelines: potential benefits, limitations, and harms of clinical guidelines BMJ 318(7182) 527-530

29. van Baalen S and Boon M (2015) An epistemological shift: from evidence-based medicine to epistemological responsibility J Eval Clin Pract 21(3) 433-439

30. Benjamin DM, Mandel DR, and Barnes T, et al (2021) Can oncologists predict the efficacy of treatments in randomized trials? Oncologist 26(1) 56-62

31. Ethun CG, Bilen MA, and Jani AB, et al (2017) Frailty and cancer: implications for oncology surgery, medical oncology, and radiation oncology CA Cancer J Clin 67(5)362-377

32. Feliu J, Heredia-Soto V, and Girones R, et al (2018) Can we avoid the toxicity of chemotherapy in elderly cancer patients? Crit Rev Oncol Hematol 131 16-23

33. Al-Mansour Z, Pang L, and Bathini V (2019) Novel cancer therapeutics in geriatrics: what is unique to the aging patient? Drugs Aging 36(1) 1-11

34. Dunn C, Wilson A, and Sitas F (2017) Older cancer patients in cancer clinical trials are underrepresented Systematic literature review of almost 5000 meta- and pooled analyses of phase III randomized trials of survival from breast, prostate and lung cancer Cancer Epidemiol 51 113-117

35. Ludmir EB, Mainwaring W, and Lin TA, et al (2019) Factors associated with age disparities among cancer clinical trial participants JAMA Oncol 5(12) 1769-1773

36. Fries JF and Krishnan E (2004) Equipoise, design bias, and randomized controlled trials: the elusive ethics of new drug development Arthritis Res Ther 6(3) R250-R255

37. Lexchin $J$ (2012) Those who have the gold make the evidence: how the pharmaceutical industry biases the outcomes of clinical trials of medications Sci Eng Ethics 18(2) 247-261

38. Ahn R, Woodbridge A, and Abraham A, et al (2017) Financial ties of principal investigators and randomized controlled trial outcomes: cross sectional study BMJ $356 \mathrm{i} 6770$

39. Sandman L and Liliemark J (2017) From evidence-based to hope-based medicine? Ethical aspects on conditional market authorization of and early access to new cancer drugs Semin Cancer Biol 45 58-63

40. Haque W, Alvarenga M, and Hsiehchen D (2020) Nonresearch pharmaceutical industry payments to oncology physician editors Oncologist 25(6) e986-e989 
41. Brogan AP, DeMuro C, and Barrett AM, et al (2017) Payer perspectives on patient-reported outcomes in health care decision making: oncology examples J Manag Care Spec Pharm 23(2) 125-134

42. Ismail Z, Peacock SJ, and Kovacic L, et al (2017) Cost-effectiveness impacts cancer care funding decisions in british Columbia, Canada, evidence from 1998 to 2008 Int J Technol Assess Health Care 33(4) 481-486

43. Buchkowsky SS and Jewesson PJ (2004) Industry sponsorship and authorship of clinical trials over 20 years Ann Pharmacother 38(4) 579-585

44. Knox KS, Adams JR, and Djulbegovic B, et al (2000) Reporting and dissemination of industry versus non-profit sponsored economic analyses of six novel drugs used in oncology Ann Oncol 11(12) 1591-1595

45. Peppercorn J, Blood E, and Winer E, et al (2007) Association between pharmaceutical involvement and outcomes in breast cancer clinical trials Cancer 109(7) 1239-1246

46. Clifford TJ, Barrowman NJ, and Moher D (2002) Funding source, trial outcome and reporting quality: are they related? Results of a pilot study BMC Health Serv Res 2(1) 18

47. Liang F, Zhu J, and Mo M, et al (2018) Role of industry funders in oncology RCTs published in high-impact journals and its association with trial conclusions and time to publication Ann Oncol 29(10) 2129-2134

48. Ocana A and Tannock IF (2011) When are "positive" clinical trials in oncology truly positive? J Natl Cancer Inst 103(1) 16-20

49. Kilari D and Mohile SG (2012) Management of cancer in the older adult Clin Geriatr Med 28(1) 33-49

50. Cressman S, Browman GP, and Hoch JS, et al (2015) A time-trend economic analysis of cancer drug trials Oncologist 20(7) 729-736

51. Gyawali B, de Vries EGE, and Dafni U, et al (2021) Biases in study design, implementation, and data analysis that distort the appraisal of clinical benefit and ESMO-Magnitude of Clinical Benefit Scale [ESMO-MCBS] scoring ESMO Open 6(3) 100117

52. Soleimani F and Zenios S (2011) Disrupting incrementalism in health care innovation Ann Surg 254(2) 203-208

53. Haynes RB, Devereaux PJ, and Guyatt GH (2002) Physicians' and patients' choices in evidence based practice BMJ 324(7350) 1350

54. Vallet-Regi M, Manzano M, and Rodriguez-Manas L, et al (2017) Management of cancer in the older age person: an approach to complex medical decisions Oncologist 22(3) 335-342

55. Nguyen H, Moreno-Agostino D, and Chua KC, et al (2021) Trajectories of healthy ageing among older adults with multimorbidity: a growth mixture model using harmonised data from eight ATHLOS cohorts PLoS One 16(4) e0248844

56. Garrido MM, Prigerson HG, and Bao Y, et al (2016) Chemotherapy use in the months before death and estimated costs of care in the last week of life J Pain Symptom Manage 51(5) 875-881

57. Langton JM, Reeve R, and Srasuebkul P, et al (2016) Health service use and costs in the last 6 months of life in elderly decedents with a history of cancer: a comprehensive analysis from a health payer perspective $\mathrm{Br} J$ Cancer 114(11) 1293-1302

58. Pitson G, Matheson L, and Garrard B, et al (2020) Population-based analysis of radiotherapy and chemotherapy treatment in the last month of life within regional Australia Intern Med J 50(5) 596-602

59. Hu J, Aprikian AG, and Vanhuyse M, et al (2019) Cancer drug use in the last month of life in men with castration-resistant prostate cancer J Oncol Pract 15(6) e510-e519

60. Cheung MC, Earle CC, and Rangrej J, et al (2015) Impact of aggressive management and palliative care on cancer costs in the final month of life Cancer 121(18) 3307-3315

61. Artz AS (2016) Biologic vs physiologic age in the transplant candidate Hematology Am Soc Hematol Educ Program 2016(1) 99-105

62. Soto-Perez-de-Celis E, Li D, and Yuan Y, et al (2018) Functional versus chronological age: geriatric assessments to guide decision making in older patients with cancer Lancet Oncol 19(6) e305-e316 
63. Ploussard G, Albrand G, and Rozet F, et al (2014) Challenging treatment decision-making in older urologic cancer patients World J Urol 32(2) 299-308

64. Colloca G, Di Capua B, and Bellieni A, et al (2020) Biological and functional biomarkers of aging: definition, characteristics, and how they can impact everyday cancer treatment Curr Oncol Rep 22(11) 115

65. Pamoukdjian F, Liuu E, and Caillet P, et al (2019) How to optimize cancer treatment in older patients: an overview of available geriatric tools Am J Clin Oncol 42(2) 109-116

66. O'Donovan A and Leech M (2020) Personalised treatment for older adults with cancer: the role of frailty assessment Tech Innov Patient Support Radiat Oncol 16 30-38

67. Overcash J, Ford N, and Kress E, et al (2019) Comprehensive geriatric assessment as a versatile tool to enhance the care of the older person diagnosed with cancer Geriatrics [Basel] 4(2) 39

68. Gomes F, Lewis A, and Morris R, et al (2020) The care of older cancer patients in the United Kingdom Ecancermedicalscience 141101

69. Tranvag EJ, Norheim OF, and Ottersen T (2018) Clinical decision making in cancer care: a review of current and future roles of patient age BMC Cancer 18(1) 546

70. DuMontier C, Loh KP, and Bain PA, et al (2020) Defining undertreatment and overtreatment in older adults with cancer: a scoping literature review J Clin Oncol 38(22) 2558-2569

71. Djulbegovic B, Elqayam S, and Dale W (2018) Rational decision making in medicine: implications for overuse and underuse J Eval Clin Pract 24(3) 655-665

72. Simcock R and Wright J (2020) Beyond performance status Clin Oncol [R Coll Radiol] 32(9) 553-561

73. Arnold M, Rutherford MJ, and Bardot A, et al (2019) Progress in cancer survival, mortality, and incidence in seven high-income countries 1995-2014 [ICBP SURVMARK-2]: a population-based study Lancet Oncol 20(11) 493-505

74. Friedenreich CM, Ryder-Burbidge C, and McNeil J (2021) Physical activity, obesity and sedentary behavior in cancer etiology: epidemiologic evidence and biologic mechanisms Mol Oncol 15(3) 790-800

75. Cortes-Ibanez FO, Nagaraj SB, and Cornelissen L, et al (2021) Prediction of incident cancers in the lifelines population-based cohort Cancers [Basel] 13(9) 2133

76. Balducci L and Dolan D (2016) Palliative care of cancer in the older patient Curr Oncol Rep 18(12) 70

77. Galvin AE, Friedman DB, and Hebert JR (2021) Focus on disability-free life expectancy: implications for health-related quality of life Qual Life Res 30(8) 2187-2195

78. Grippo F, Desesquelles A, and Pappagallo M, et al (2020) Multi-morbidity and frailty at death: a new classification of death records for an ageing world Popul Stud [Camb] 74(3) 437-449

79. Ezzatvar Y, Ramirez-Velez R, and Saez de Asteasu ML, et al (2020) Physical function and all-cause mortality in older adults diagnosed with cancer: a systematic review and meta-analysis J Gerontol A Biol Sci Med Sci 76(8) 1447-1453

80. Verduzco-Aguirre HC, Gomez-Moreno C, and Chavarri-Guerra Y, et al (2019) Predicting life expectancy for older adults with cancer in clinical practice: implications for shared decision-making Curr Oncol Rep 21(8) 68

81. McMaughan DJ, Oloruntoba O, and Smith ML (2020) Socioeconomic status and access to healthcare: interrelated drivers for healthy aging Front Public Health 8231

82. Zhang YB, Pan XF, and Chen J, et al (2020) Combined lifestyle factors, incident cancer, and cancer mortality: a systematic review and meta-analysis of prospective cohort studies Br J Cancer 122(7) 1085-1093

83. Ezzatvar Y, Ramirez-Velez R, and Saez de Asteasu ML, et al (2021) Cardiorespiratory fitness and all-cause mortality in adults diagnosed with cancer systematic review and meta-analysis Scand J Med Sci Sports 31(9) 1745-1752 
84. Revenig LM, Canter DJ, and Taylor MD, et al (2013) Too frail for surgery? Initial results of a large multidisciplinary prospective study examining preoperative variables predictive of poor surgical outcomes J Am Coll Surg 217(4) 665-70 e1

85. Boulahssass R, Gonfrier S, and Ferrero JM, et al (2018) Predicting early death in older adults with cancer Eur J Cancer $10065-74$

86. Lewis MA (2021) ASCO 2021's Best Trials Proved We Can Do More With Less (Medscape) Date accessed: 14/7/21

87. Baltatzis M, Rodriquenz MG, and Siriwardena AK, et al (2021) Contemporary management of pancreas cancer in older people Eur J Surg Oncol 47(3 Pt A) 560-568

88. de Boer AZ, de Glas NA, and Marang-van de Mheen PJ, et al (2020) Effect of omission of surgery on survival in patients aged 80 years and older with early-stage hormone receptor-positive breast cancer Br J Surg 107(9) 1145-1153

89. Kotwal AA and Walter LC (2020) Cancer screening among older adults: a geriatrician's perspective on breast, cervical, colon, prostate, and lung cancer screening Curr Oncol Rep 22(11) 108

90. Schoenborn NL, Huang J, and Sheehan OC, et al (2019) Influence of age, health, and function on cancer screening in older adults with limited life expectancy J Gen Intern Med 34(1) 110-117

91. Attena $F(2019)$ Too much medicine? Scientific and ethical issues from a comparison between two conflicting paradigms BMC Public Health 19(1) 97

92. Hebar A, Valent P, and Selzer E (2013) The impact of molecular targets in cancer drug development: major hurdles and future strategies Expert Rev Clin Pharmacol 6(1) 23-34

93. Fox B, de Toro Carmena M, and Alvarez Alvarez R, et al (2020) Efficacy and safety of immune checkpoint inhibitor immunotherapy in elderly cancer patients Clin Transl Oncol 22(4) 555-562

94. Rzeniewicz K, Larkin J, and Menzies AM, et al (2021) Immunotherapy use outside clinical trial populations: never say never? Ann Oncol 32(7) 866-880

95. Elias R and Odejide O (2019) Immunotherapy in older adults: a checkpoint to palliation? Am Soc Clin Oncol Educ Book 39 e110-e20

96. Battisti NML, Liposits G, and De Glas NA, et al (2020) Systemic therapy of common tumours in older patients: challenges and opportunities. A young International Society of Geriatric Oncology review paper Curr Oncol Rep 22(10) 98

97. Ingleby FC, Woods LM, and Atherton IM, et al (2021) Describing socio-economic variation in life expectancy according to an individual's education, occupation and wage in England and Wales: an analysis of the ONS Longitudinal Study SSM Popul Health 14100815

98. Balachandran A, James KS, and van Wissen L, et al (2021) Can changes in education alter future population ageing in Asia and Europe? J Biosoc Sci 30 1-13

99. Seligson ND, Knepper TC, and Ragg S, et al (2021) Developing drugs for tissue-agnostic indications: a paradigm shift in leveraging cancer biology for precision medicine Clin Pharmacol Ther 109(2) 334-342

100. Tonelli MR (2018) Clinical judgement in precision medicine J Eval Clin Pract 24(3) 646-648

101. Ozdogan M, Papadopoulou E, and Tsoulos N, et al (2021) Comprehensive tumor molecular profile analysis in clinical practice BMC Med Genomics 14(1) 105

102. Sartor O, de Bono J, and Chi KN, et al (2021) Lutetium-177-PSMA-617 for metastatic castration-resistant prostate cancer N Engl J Med 385 1091-1103

103. Leibowitz R, Davidson T, and Gadot M, et al (2020) A retrospective analysis of the safety and activity of Lutetium-177-prostate-specific membrane antigen radionuclide treatment in older patients with metastatic castration-resistant prostate cancer Oncologist 25(9) 787-792 
104. White MC, Holman DM, and Boehm JE, et al (2014) Age and cancer risk: a potentially modifiable relationship Am J Prev Med 463 Suppl 1) $\mathrm{S} 7-\mathrm{S} 15$

105. Holliday R (2006) Aging is no longer an unsolved problem in biology Ann N Y Acad Sci 1067 1-9

106. Li Y, Schoufour J, and Wang DD, et al (2020) Healthy lifestyle and life expectancy free of cancer, cardiovascular disease, and type 2 diabetes: prospective cohort study BMJ 36816669

107. Carmona JJ and Michan S (2016) Biology of healthy aging and longevity Rev Invest Clin 68(1) 7-16

108. Dorling JL, Martin CK, and Redman LM (2020) Calorie restriction for enhanced longevity: the role of novel dietary strategies in the present obesogenic environment Ageing Res Rev 64101038

109. Duran-Ortiz S, List EO, and Basu R, et al (2021) Extending lifespan by modulating the growth hormone/insulin-like growth factor-1 axis: coming of age Pituitary 24(3) 438-456

110. Pozuelo-Carrascosa DP, Alvarez-Bueno C, and Cavero-Redondo I, et al (2019) Cardiorespiratory fitness and site-specific risk of cancer in men: a systematic review and meta-analysis Eur J Cancer 113 58-68

111. Stegmann ME, Brandenbarg D, and Reyners AKL, et al (2021) Treatment goals and changes over time in older patients with noncurable cancer Support Care Cancer 29(7) 3849-3856

112. Puts MTE, Strohschein FJ, and Del Giudice ME, et al (2018) Role of the geriatrician, primary care practitioner, nurses, and collaboration with oncologists during cancer treatment delivery for older adults: a narrative review of the literature J Geriatr Oncol 9(4) 398-404

113. Firkins J, Hansen L, and Driessnack M, et al (2020) Quality of life in 'chronic' cancer survivors: a meta-analysis J Cancer Surviv 14(4) 504-517

114. Mead KH, Raskin S, and Willis A, et al (2020) Identifying patients' priorities for quality survivorship: conceptualizing a patient-centered approach to survivorship care J Cancer Surviv 14(6) 939-958

115. Thiessen M, Sinclair S, and Tang PA, et al (2020) Information access and use by patients with cancer and their friends and family: development of a grounded theory J Med Internet Res 22(10) e20510

116. Al Achkar M, Marchand L, and Thompson M, et al (2020) Unmet needs and opportunities for improving care for patients with advanced lung cancer on targeted therapies: a qualitative study BMJ Open 10(3) e032639

117. Bijlsma RM, Wouters RHP, and Wessels $\mathrm{H}$, et al (2018) Managing unsolicited findings in genomics: a qualitative interview study with cancer patients Psychooncology 27(4) 1327-1333

118. Yang W, Staps T, and Hijmans E (2010) Existential crisis and the awareness of dying: the role of meaning and spirituality Omega (Westport) 61(1) 53-69

119. Stanic J, Perrenoud B, and Rochat E, et al (2018) Experiences of newly diagnosed cancer patients in confronting the finitudes of life: a qualitative systematic review protocol JBI Database System Rev Implement Rep 16(12) 2288-2294

120. De Silva D, Ranasinghe W, and Bandaragoda T, et al (2018) Machine learning to support social media empowered patients in cancer care and cancer treatment decisions PLoS One 13(10) e0205855

121. Treffers T and Putora PM (2020) Emotions as social information in shared decision-making in Oncology Oncology 98(6) 430-437

122. Mighton C, Carlsson L, and Clausen M, et al (2019) Development of patient 'profiles' to tailor counseling for incidental genomic sequencing results Eur J Hum Genet 27(7) 1008-1017

123. Weiss J, Kirchberger MC, and Heinzerling L (2020) Therapy preferences in melanoma treatment-willingness to pay and preference of quality versus length of life of patients, physicians, healthy individuals and physicians with oncological disease Cancer Med 9(17) $6132-6140$ 
124. Greer JA, Applebaum AJ, and Jacobsen JC, et al (2020) Understanding and addressing the role of coping in palliative care for patients with advanced cancer J Clin Oncol 38(9) 915-925

125. Abernethy AP and Grubbs SS (2014) Managing cumulative expectations in oncology: challenges and potential solutions Am Soc Clin Oncol Educ Book 34 e140- e144

126. Shah M, Ferguson A, and Corn PD, et al (2021) Developing workshops to enhance hope among patients with metastatic breast cancer and oncologists: a pilot study JCO Oncol Pract 17(6) e785-e93

127. Nipp RD, Greer JA, and El-Jawahri A, et al (2017) Coping and prognostic awareness in patients with advanced cancer J Clin Oncol 35(22) 2551-2557

128. Brewer NT, DeFrank JT, and Gilkey MB (2016) Anticipated regret and health behavior: a meta-analysis Health Psychol 35(11) 1264-1275

129. Maguire R, Hanly P, and Drummond FJ, et al (2017) Regret and fear in prostate cancer: the relationship between treatment appraisals and fear of recurrence in prostate cancer survivors Psychooncology 26(11) 1825-1831

130. Vickers AJ (2017) Decisional conflict, regret, and the burden of rational decision making Med Decis Making 37(1) 3-5

131. Reimann M, Nenkov GY, and Maclnnis D, et al (2014) The role of hope in financial risk seeking J Exp Psychol Appl 20(4) 349-364

132. Bennett M, Mullard R, and Adam MTP, et al (2020) Going, going, gone: competitive decision-making in Dutch auctions Cogn Res Princ Implic 5(1) 62

133. Hoverman JR (2020) Rethinking clinical oncology drug research in an era of value-based cancer care: a role for chemotherapy pathways Cancer Med 9(15) 5306-5311

134. Massa I, Balzi W, and Altini M, et al (2018) The challenge of sustainability in healthcare systems: frequency and cost of diagnostic procedures in end-of-life cancer patients Support Care Cancer 26(7) 2201-2208

135. Bernacki RE, Block SD, and American College of Physicians High Value Care Task F (2014) Communication about serious illness care goals: a review and synthesis of best practices JAMA Intern Med 174(12) 1994-2003

136. Nicolai J, Buchholz A, and Seefried N, et al (2016) When do cancer patients regret their treatment decision? A path analysis of the influence of clinicians' communication styles and the match of decision-making styles on decision regret Patient Educ Couns 99(5) 739-746

137. Wen FH, Chen JS, and Chang WC, et al (2019) Accurate prognostic awareness and preference states influence the concordance between terminally ill cancer patients' states of preferred and received life-sustaining treatments in the last 6 months of life Palliat Med 33(8) 1069-1079

138. Greer JA, Jacobs JM, and El-Jawahri A, et al (2018) Role of patient coping strategies in understanding the effects of early palliative care on quality of life and mood J Clin Oncol 36(1) 53-60

139. Maltoni M, Scarpi E, and Dall'Agata M, et al (2016) Systematic versus on-demand early palliative care: a randomised clinical trial assessing quality of care and treatment aggressiveness near the end of life Eur J Cancer 69 110-118

140. Ryan S, Wong J, and Chow R, et al (2020) Evolving definitions of palliative care: upstream migration or confusion? Curr Treat Options Oncol 21(3) 20

141. Vanbutsele G, Pardon K, and Van Belle S, et al (2018) Effect of early and systematic integration of palliative care in patients with advanced cancer: a randomised controlled trial Lancet Oncol 19(3) 394-404

142. Brighton LJ and Bristowe $\mathrm{K}$ (2016) Communication in palliative care: talking about the end of life, before the end of life Postgrad Med J 92(1090) 466-470

143. van Leeuwen KM, van Loon MS, and van Nes FA, et al (2019) What does quality of life mean to older adults? A thematic synthesis PLoS One 14(3) e0213263 
144. Staats K, Grov EK, and Husebo BS, et al (2020) Dignity and loss of dignity: experiences of older women living with incurable cancer at home Health Care Women Int 41(9) 1036-1058

145. Balducci L (2019) Geriatric oncology, spirituality, and palliative care J Pain Symptom Manage 57(1) 171-175

146. Gillman J (2019) Memoirs and the Ars Moriendi J Pastoral Care Counsel 73(3) 160-168

147. Kaasa S, Loge JH, and Aapro M, et al (2018) Integration of oncology and palliative care: a Lancet Oncology Commission Lancet Oncol 19(11) e588-e653

148. Evans CJ, Ison L, and Ellis-Smith C, et al (2019) Service delivery models to maximize quality of life for older people at the end of life: a rapid review Milbank Q 97(1) 113-175

149. Wildes TM, O'Donovan A, and Colloca GF, et al (2018) Tumour boards in geriatric oncology Age Ageing 47(2) 168-170

150. Stacey D, Legare F, and Lewis K, et al (2017) Decision aids for people facing health treatment or screening decisions Cochrane Database Syst Rev 4 CD001431

151. lijima K, Arai $\mathrm{H}$, and Akishita M, et al (2021) Toward the development of a vibrant, super-aged society: the future of medicine and society in Japan Geriatr Gerontol Int 21 601-613

152. Alvarnas J (2019) From the editor-in-chief: oncology in the time of 'Moore's Law' Am J Manag Care 25(5 Spec No.) SP140

153. Lohr S (2021) What Ever Happened to IBM's Watson? (The New York Times) Date accessed: 16/7/21

154. Chin-Yee B and Upshur R (2019) Three problems with big data and artificial intelligence in medicine Perspect Biol Med 62(2):237-256

155. Adriaans DJ, Dierick-van Daele AT, and van Bakel M, et al (2021) Digital self-management support tools in the care plan of patients with cancer: review of randomized controlled trials J Med Internet Res 23(6) e20861

156. Ostropolets A, Zhang L, and Hripcsak G (2020) A scoping review of clinical decision support tools that generate new knowledge to support decision making in real time J Am Med Inform Assoc 27(12) 1968-1976

157. Berry DL, Blonquist TM, and Patel RA, et al (2015) Exposure to a patient-centered, Web-based intervention for managing cancer symptom and quality of life issues: impact on symptom distress J Med Internet Res 17(6) e136

158. Lavallee DC, Chenok KE, and Love RM, et al (2016) Incorporating patient-reported outcomes into health care to engage patients and enhance care Health Aff (Millwood) 35(4) 575-582

159. Kelly CJ, Karthikesalingam A, and Suleyman M, et al (2019) Key challenges for delivering clinical impact with artificial intelligence BMC Med 17(1) 195

160. Apweiler R, Beissbarth T, and Berthold MR, et al (2018) Whither systems medicine? Exp Mol Med 50(3) e453

161. Josfeld L, Keinki C, and Pammer C, et al (2021) Cancer patients' perspective on shared decision-making and decision aids in oncology J Cancer Res Clin Oncol 147(6) 1725-1732

162. Shahrokni A, Alexander K, and Wildes TM, et al (2018) Preventing treatment-related functional decline: strategies to maximize resilience Am Soc Clin Oncol Educ Book 38 415-431

163. DuMontier C, Loh KP, and Soto-Perez-de-Celis E, et al (2021) Decision making in older adults with cancer J Clin Oncol 39(19) 21642174

164. Lin FP, Groza T, and Kocbek S, et al (2018) Cancer care treatment outcome ontology: a novel computable ontology for profiling treatment outcomes in patients with solid tumors JCO Clin Cancer Inform 2 1-14

165. Cesario A, D'Oria M, and Calvani R, et al (2021) The role of artificial intelligence in managing multimorbidity and cancer J Pers Med 11(4) 314 